\section{Contemporary assessment of coronary hemodynamics in the catheter laboratory}

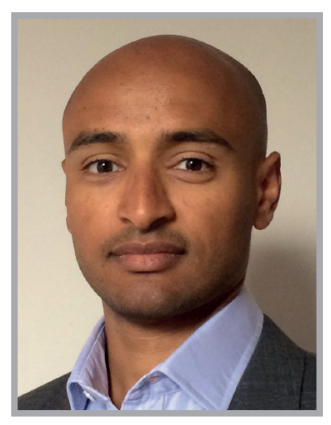

\author{
"20 years of high-quality coronary physiological \\ research in the development and validation of \\ fractional flow reserve has identified the \\ importance of assessing the functional \\ significance of coronary stenoses and using this \\ to direct therapy."
}

\begin{abstract}
Kaleab N Asrress ${ }^{*, 1}$, Usaid Allahwala1 \& Ravinay Bhindi
\end{abstract}
First draft submitted: 9 May 2016; Accepted for publication: 1 September 2016; Published online: 28 October 2016

\section{Background}

Despite advances in noninvasive imaging, coronary angiography remains the gold-standard imaging modality for the anatomical characterization of coronary artery stenoses. However, coronary angiography alone does not accurately correlate with the hemodynamics of the coronary circulation to guide management strategies. This requires an understanding of the impact of epicardial coronary disease as well as microcirculatory function on myocardial blood supply. Pathological processes can affect each of these components that can impact on patient symptomatology, and should ultimately be evaluated to guide treatment strategies. In this short overview of the current state of the art, we review the techniques and technologies that can be used to assess epicardial and microvascular disease, as well as emerging technologies that have potential to impact clinical practice.

\section{Pressure assessment of coronary artery disease}

The physiological assessment of atherosclerotic lesions by measuring coronary pressure is not a new concept. In 1974, Gould and colleagues published their seminal work on the relationship between the severity of coronary flow restriction, resting and maximal coronary blood flow, and regional flow [1]. It was not until the 1990s, following the introduction of ultrathin 0.015 -inch coronary guide-wires, and the groundbreaking work of Pijls and De Bruyne that the concept of fractional flow reserve (FFR) was introduced [2]. FFR is a lesion-specific index defined as the ratio of maximal hyperemic myocardial blood flow, or maximum vasodilatation, across a stenotic artery to the maximal myocardial blood flow across the same artery in the theoretical absence of the stenosis. By applying Ohm's Law, at maximal hyperemia where resistance is assumed to be

\section{KEYWORDS}

- catheter - coronary artery disease

- coronary physiology - fractional flow reserve

'Department of Cardiology, Royal North Shore Hospital, Sydney, Kolling Institute, University of Sydney, Sydney, 2065, 


\section{“The major limitation of coronary flow reserve is the inability to separate the epicardial and microcirculatory components to flow impedance."}

minimal and constant, pressure can be used as a surrogate marker of flow. Since the pressure in a normal coronary artery is equivalent to aortic pressure $\left(\mathrm{P}_{\mathrm{a}}\right)$, the FFR can simply be derived as a ratio of the mean distal coronary pressure $\left(\mathrm{P}_{\mathrm{d}}\right)$ at a point past the stenosis to the $\mathrm{P}_{\mathrm{a}}$ during maximal hyperemia where FFR $=\mathrm{P}_{\mathrm{d}} / \mathrm{P}_{\mathrm{a}}$. By 1996, Pijls and colleagues published their landmark paper, in which they compared the validity of FFR to accurately detect hemodynamically significant lesions that appeared only moderate in severity on angiography against established noninvasive measures of myocardial ischemia, namely thallium scintigraphy, bicycle exercise testing and dobutamine stress echocardiography [3]. Three important studies have followed, DEFER, FAME and FAME II, which have firmly established FFR as an integral tool in the assessment of coronary artery disease severity $[4,5]$, receiving class I, level of evidence $A$ in the latest European Society of Cardiology guidelines to assess the presence of ischemia to guide revascularization decisions [6].

\section{Beyond FFR}

While FFR is the best validated, several other indices of coronary physiology have been proposed to guide clinical decision-making. Large randomized studies are underway, which may bring them intimately into everyday clinical practice.

\section{- Instantaneous wave-free ratio}

One of the limitations to adoption of physiologically guided revascularization is the need for the administration of pharmacological vasodilators. The instantaneous wave-free ratio has been proposed as a new pressure-derived index of stenosis severity that may circumnavigate this issue $[7,8]$. As with FFR, instantaneous wave-free ratio (iFR) also relies on the proportional relationship of pressure and flow that occurs with constant intracoronary resistance. However, instead of requiring pharmacological vasodilatation to achieve this, it is measured over a diastolic wave-free period in the cardiac cycle where intracoronary resistance is naturally constant. $\mathrm{iFR}$ is calculated as the ratio of distal to proximal pressures over this wave-free period. While it is a new player in the field, iFR has been shown to be comparable to FFR in terms of diagnostic categorization over a wide spectrum of coronary stenosis severities [9]. Several large iFR versus FFR head-to-head randomized outcome studies are currently underway which should inform the clinical utility of iFR in contemporary practice.

\section{- Coronary flow reserve}

Coronary flow reserve (CFR) is defined as the ratio of hyperemic blood flow $\left(\mathrm{Q}_{\max }\right)$ to resting myocardial blood flow $\left(\mathrm{Q}_{\text {rest }}\right)$, where $\mathrm{CFR}=\mathrm{Q}_{\max } / \mathrm{Q}_{\text {rest }}$. It is a combined measure of the capacity of the major resistance components, namely the epicardial coronary artery and supplied myocardial vascular bed, to achieve maximal blood flow under hyperemic stimulation. Since absolute myocardial flow is not easy to determine, surrogates of flow are used, including flow velocities assessed by a Doppler wire (FloWire ${ }^{\circledR}$ or ComboWire ${ }^{\circledR}$, Volcano, Philips Healthcare, Best, The Netherlands) or mean transit time thermodilution using a PressureWire $^{\mathrm{TM}}$ (St Jude Medical, MN, USA). The major limitation of CFR is the inability to separate the epicardial and microcirculatory components to flow impedance.

\section{- Hyperemic stenosis resistance index}

Advances in sensor wire technology have allowed pressure and velocity sensors to be combined onto a single wire (ComboWire ${ }^{\circledR}$, Philips Healthcare). This provides hemodynamic information on the physiological state of the entire coronary circulation. By combining simultaneous measurements of the phasic pressure and Doppler velocity distal to a stenosis, a calculation of stenosis and microvascular resistances (see hyperemic microvascular resistance [HMR] below) can be made. This index provides a physiological means of quantifying the impediment to maximal flow caused exclusively by the stenosis. Like FFR, it is independent of basal hemodynamic conditions, with high reproducibility and low variability [10]. It was found to have a higher diagnostic accuracy than FFR [11], and therefore provides a more refined assessment of stenosis severity. Despite the excellent clinical experimental work, hyperemic stenosis resistance (HSR) has failed to gain traction in clinical care, primarily because of the cost of the wires, the technical challenge of obtaining the measurements, as well as the success of FFR. Basal stenosis resistance is calculated in the same way as HSR but without pharmacological vasodilation, and is another candidate as an adenosine-free assessment of lesion severity [12].

Simultaneous pressure and flow recordings also allow individual pressure and velocity waves to be analyzed, a process called wave intensity analysis, which has provided a further avenue to study the physiology of the coronary circulation [13-15]. 


\section{Coronary microcirculation}

The state of the coronary microcirculation is an important determinant of patient outcomes in several clinical settings including acute coronary syndromes, coronary intervention, angina in the context of nonobstructed coronary arteries, hypertensive heart disease, diabetes mellitus and aortic stenosis [16]. Two simple tests exist to interrogate the coronary microcirculation, though algorithms to utilize the information that they provide clinically are not widely employed. CFR can also be used, but has its limitations as described above.

\section{- Hyperemic microvascular resistance}

Using techniques to measure phasic pressure and velocity similar to those used for the measurement of HSR, an assessment of microvascular resistance at hyperemia can be made such that:

$$
\mathrm{HMR}=\mathrm{P}_{\mathrm{d}} / \mathrm{V}
$$

Where $\mathrm{P}_{\mathrm{d}}$ is the distal coronary pressure, and $\mathrm{v}$ is the average peak Doppler velocity. This is based on application of Ohm's law, where resistance is equal to pressure divided by flow. This index is pressure dependent, such that in the context of an epicardial stenosis, HMR is higher than post percutaneous intervention in the same vessel, where local autoregulatory processes modulate microvascular tone, despite hyperemic stimulation [17]. Emerging data suggest that HMR may hold advantages over the more established index of microvascular resistance (IMR; see below) in the assessment of microvascular function [18].

\section{Index of microvascular resistance}

This index is used to assess microvascular resistance. Also based on Ohm's Law, it uses distal coronary pressure and thermodilution-derived flow:

$$
\begin{aligned}
\operatorname{IMR} & =\mathrm{P}_{\mathrm{d}} /\left(1 / \mathrm{T}_{\mathrm{mn}}\right) \\
& =\mathrm{P}_{\mathrm{d}} \cdot \mathrm{T}_{\mathrm{mn}}
\end{aligned}
$$

where $P_{d}$ is the distal coronary pressure and $T_{m n}$ is the mean transit time of a bolus of saline injected at room temperature into the coronary artery at maximal hyperemia. The inverse of $T_{m n}$ strongly correlates to absolute coronary blood flow.

An IMR $>30$ suggests abnormal microvascular resistance. It has been shown to be an independent predictor of acute and short-term myocardial damage, an early marker of myocardial viability, LV recovery and long-term outcome in patients undergoing primary percutaneous coronary intervention for ST-elevation myocardial infarction [19]. The importance of microvascular disease causing ischemia, in the absence of overt epicardial disease is increasingly recognized as a major determinant of morbidity. Carefully executed studies are required to instruct the optimal management of this patient subset.

\section{- Zero-flow pressure}

The concept of 'zero-flow' pressure has recently been introduced and shows promise as a refined assessment of microvascular function in patients suffering with ST-elevation myocardial infarction. Zero-flow pressure requires the use of a combined pressure and flow wire and is defined as the distal coronary pressure when flow in the coronary artery would cease, and was found to be a better predictor of the extent of myocardial infarction on cardiac MRI compared with HMR and IMR [20]. Further studies are required to establish its clinical utility.

\section{Conclusion}

20 years of high-quality coronary physiological research in the development and validation of FFR has identified the importance of assessing the functional significance of coronary stenoses and using this to direct therapy. When utilized correctly, this identifies patients who potentially benefit from revascularization as well as those best treated with optimal medical therapy, an approach that results in improved morbidity and clinical outcomes, shortens procedure times and has economic benefit. Beyond FFR, other catheter-based physiological methods have vastly improved our understanding of the coronary circulation. Future descriptive studies using these advanced techniques are likely to provide more insight and further refine the therapeutic strategy, which in turn should result in improved patient outcomes.

\section{Financial \& competing interests disclosure}

The authors have no relevant affliations or financial involvement with any organization or entity with a financial interest in or financial conflict with the subject matter or materials discussed in the manuscript. This includes employment, consultancies, honoraria, stock ownership or options, expert testimony, grants or patents received or pending, or royalties.

No writing assistance was utilized in the production of this manuscript.

\section{“...this identifies patients who potentially benefit from revascularization as well as those best treated with optimal medical therapy, an approach that results in improved morbidity and clinical outcomes, shortens procedure times and has economic benefit."}




\section{References}

1 Gould KL, Lipscomb K, Hamilton GW. Physiologic basis for assessing critical coronary stenosis. Instantaneous flow response and regional distribution during coronary hyperemia as measures of coronary flow reserve. Am. J. Cardiol. 33(1), 87-94 (1974).

2 Pijls NH, van Son JA, Kirkeeide RL, De Bruyne B, Gould KL. Experimental basis of determining maximum coronary, myocardial, and collateral blood flow by pressure measurements for assessing functional stenosis severity before and after percutaneous transluminal coronary angioplasty. Circulation 87(4), 1354-1367 (1993).

3 Pijls NH, De Bruyne B, Peels K et al. Measurement of fractional flow reserve to assess the functional severity of coronaryartery stenoses. N. Engl. J. Med. 334(26), 1703-1708 (1996).

4 Tonino PA, De Bruyne B, Pijls NH et al. Fractional flow reserve versus angiography for guiding percutaneous coronary intervention. N. Engl. J. Med. 360 (3), 213-224 (2009).

5 De Bruyne B, Pijls NH, Kalesan B et al. Fractional flow reserve-guided $\mathrm{PCI}$ versus medical therapy in stable coronary disease. N. Engl. J. Med. 367(11), 991-1001 (2012).

6 Windecker S, Kolh P, Alfonso F et al. 2014 ESC/EACTS guidelines on myocardial revascularization: the task force on myocardial revascularization of the European Society of Cardiology (ESC) and the European Association for Cardio-Thoracic Surgery (EACTS) developed with the special contribution of the European Association of Percutaneous Cardiovascular Interventions (EAPCI). Eur. Heart J. 35(37), 2541-2619 (2014).

7 Sen S, Escaned J, Malik IS et al. Development and validation of a new adenosine- independent index of stenosis severity from coronary wave-intensity analysis: results of the ADVISE (Adenosine Vasodilator Independent Stenosis Evaluation) study. J. Am. Coll. Cardiol. 59(15), 1392-1402 (2012).

8 Sen S, Asrress KN, Nijjer S et al. Diagnostic classification of the instantaneous wave-free ratio is equivalent to fractional flow reserve and is not improved with adenosine administration. Results of CLARIFY (Classification Accuracy of Pressure-Only Ratios Against Indices Using Flow Study). J. Am. Coll. Cardiol. 61(13), 1409-1420 (2013).

9 Petraco R, Escaned J, Sen S et al. Classification performance of instantaneous wave-free ratio (iFR) and fractional flow reserve in a clinical population of intermediate coronary stenoses: results of the ADVISE registry. EuroIntervention 9(1), 91-101 (2013).

10 Siebes M, Verhoeff BJ, Meuwissen M, de Winter RJ, Spaan JA, Piek JJ. Single-wire pressure and flow velocity measurement to quantify coronary stenosis hemodynamics and effects of percutaneous interventions. Circulation 109(6), 756-762 (2004).

11 Meuwissen M, Siebes M, Chamuleau SA et al. Hyperemic stenosis resistance index for evaluation of functional coronary lesion severity. Circulation 106(4), 441-446 (2002).

12 van de Hoef TP, Nolte F, Damman P et al. Diagnostic accuracy of combined intracoronary pressure and flow velocity information during baseline conditions: Adenosine-free assessment of functional coronary lesion severity. Circ. Cardiovasc. Interv. 5(4), 508-514 (2012).

13 Davies JE, Whinnett ZI, Francis DP et al. Evidence of a dominant backward-propagating 'suction' wave responsible for diastolic coronary filling in humans, attenuated in left ventricular hypertrophy. Circulation 113(14), 1768-1778 (2006).
14 Lockie TP, Rolandi MC, Guilcher A et al. Synergistic adaptations to exercise in the systemic and coronary circulations that underlie the warm-up angina phenomenon. Circulation 126(22), 2565-2574 (2012).

15 De Silva K, Foster P, Guilcher A et al. Coronary wave energy: a novel predictor of functional recovery after myocardial infarction. Circ. Cardiovasc. Interv. 6(2), 166-175 (2013).

16 Danson E, Hansen P, Sen S, Davies J, Meredith I, Bhindi R. Assessment, treatment, and prognostic implications of CAD in patients undergoing TAVI. Nat. Rev. Cardiol. 13(5), 276-285 (2016)

17 Verhoeff BJ, Siebes M, Meuwissen M et al. Influence of percutaneous coronary intervention on coronary microvascular resistance index. Circulation 111(1), 76-82 (2005).

18 Williams R, De Silva K, Lumley M et al. Doppler indices of resistance are superior to thermodilution indices at predicting coronary microvascular dysfunction. J. Am. Coll. Cardiol. 65(10S), A1843 (2015).

19 Fearon WF, Low AF, Yong AS et al. Prognostic value of the index of microcirculatory resistance measured after primary percutaneous coronary intervention. Circulation 127(24), 2436-2441 (2013).

20 Patel N, Petraco R, Dall'Armellina E et al. Zero-flow pressure measured immediately after primary percutaneous coronary intervention for ST-segment elevation myocardial infarction provides the best invasive index for predicting the extent of myocardial infarction at 6 months: an OxAMI Study (Oxford Acute Myocardial Infarction). JACC Cardiovasc. Interv. 8(11), 1410-1421 (2015). 